\title{
DETECTION OF QUINOLONE-RESISTANCE MUTATIONS IN SALMONELLA SPP. STRAINS OF EPIDEMIC AND POULTRY ORIGIN
}

\author{
Roberta Barreiros de Souza ${ }^{1}$, Marciane Magnani ${ }^{1}$, Rafaela Gomes Ferrari ${ }^{1}$, Luciana Bill Mikito Kottwitz ${ }^{1}$, Daniele \\ Sartori $^{2}$, Maria Cristina Bronharo Tognim ${ }^{3}$, Tereza Cristina R. M. de Oliveira ${ }^{{ }^{*}}$
}

\begin{abstract}
${ }^{1}$ Universidade Estadual de Londrina, Centro de Ciências Agrárias, Departamento de Ciência e Tecnologia de Alimentos, Londrina, PR, Brasil; ${ }^{2}$ Universidade Estadual de Londrina, Centro de Ciências Biológicas, Departamento de Biologia Geral, Londrina, PR, Brasil; ${ }^{3}$ Universidade Estadual de Maringá, Centro de Ciências Básicas da Saúde, Departamento de Análises Clínicas, Maringá, PR, Brasil.
\end{abstract}

Submitted: March 08, 2010; Returned to authors for corrections: April 23, 2010; Approved: June 21, 2010.

\begin{abstract}
Mutations into codons Aspartate-87 (62\%) and Serine-83 (38\%) in QRDR of gyrA were identified in 105 Salmonella strains resistant to nalidixic acid (94 epidemic and 11 of poultry origin). The results show a high incidence of mutations associated to quinolone resistance but suggest association with others mechanisms of resistance.
\end{abstract}

Key words: Quinolones, gyrA, Quinolone Resistance Determining Region (QRDR), AS-PCR-RFLP.

Resistance to quinolones in Salmonella spp. is mainly due to mutations that alter the binding site of the antimicrobial with DNA-gyrase, target of action of these antimicrobials. Generally, the mutations occur in a specific region of gyr $\mathrm{A}$ gene, between amino acids 67 and 106, called quinolone resistance determining region (QRDR) (11). Point mutations in the QRDR of gyrA gene may be sufficient to generate high levels of resistance of Salmonella spp. to non-fluorine quinolones such as nalidixic acid (NAL) (9). Additional mutations are necessary for resistance to fluoroquinolones (14). Fluoroquinolones are usually the antimicrobials of choice for treatment of severe or systemic human salmonellosis (12). An increase in isolation of Salmonella strains with reduced susceptibility to fluoroquinolones such as ciprofloxacin is a public health problem, since it may cause failure of clinical treatment, limiting the therapeutic options for treatment (1).
Resistance to fluoroquinolones is relatively uncommon in Salmonella spp., when compared to other genera of the Enterobacteriaceae family. However, for changes in their susceptibility NAL-resistant Salmonella strains require lower exposure to fluoroquinolones than NAL-susceptible ones (3). An increase in NAL-resistant strains with reduced susceptibility to fluoroquinolones has been observed (7). The most frequent changes in QRDR of gyrA gene in NALresistant Salmonella spp. occurs in codons corresponding to Serine-83 (Ser83) and Aspartate-87 (Asp87) (6). Strains that carry substitutions in these codons have different levels of reduced susceptibility to fluoroquinolones (10).

Aim of study was to assess mutations in the QRDR of the gyrA gene associated with resistance to the nalidixic acid and reduced susceptibility to ciprofloxacin through allele specific (AS) polymerase chain reaction (PCR) restriction fragment

*Corresponding Author. Mailing address: Departamento de Ciência e Tecnologia de Alimentos, Universidade Estadual de Londrina, Rodovia Celso Garcia Cid, PR 445, Km 380, Campus Universitário, C. P. 6001, CEP 86051-990, Londrina, Paraná, Brazil.; Tel: +55-43-3371-4565 Fax: +55-43-3371-4080.; E-mail: terezaoliveira@yahoo.com 
length polymorphisms (RFLP) (8).

A total of 123 Salmonella strains of poultry origin or associated to human salmonellosis outbreaks, resistant and susceptible to nalidixic acid, were evaluated (Table 1). The strains belonging to the nine different serovars isolated in the State of Parana, Brazil, between 1999 and 2006. The epidemic strains were provided by the Central Laboratory of the State of
Parana (LACEN, Curitiba, Parana, Brazil) and those of poultry origin were obtained from Avian Health Laboratory accredited by the Brazilian Ministry of Agriculture (MAPA, Brazil). Serotyping was performed at the Laboratory of Enterobacteria, Department of Bacteriology, Osvaldo Cruz Foundation (FIOCRUZ), Rio de Janeiro, Brazil.

Table 1. Distribution of Salmonella spp strains isolated in the period between 1999 to 2006 in the state of Parana, Brazil, according to serovar, resistance to nalidixic acid (NAL) and isolation source.

\begin{tabular}{|c|c|c|c|c|c|}
\hline $\begin{array}{c}\text { Origin } * * \\
\text { NAL } * \text { - resistant }\end{array}$ & Serovar & $\mathbf{N} * * *$ & $\begin{array}{c}\text { Origin } \\
\text { NAL- sensitive }\end{array}$ & Serovar & $\mathbf{N}$ \\
\hline Epidemic & Enteritidis & 85 & Epidemic $^{\mathrm{a}}$ & Enteritidis & 5 \\
\hline Epidemic & Typhimurium & 3 & Epidemic & Typhimurium & 1 \\
\hline Epidemic & Joannesburg & 3 & Epidemic & Oraniemburg & 1 \\
\hline Epidemic & O9:12 & 1 & Epidemic & Saintpaul & 1 \\
\hline Epidemic & Albany & 1 & Epidemic & Infantis & 2 \\
\hline Epidemic & Newport & 1 & - & $\underline{-}$ & - \\
\hline Poultry & Enteritidis & 9 & $\begin{array}{c}\text { Biological material }^{\mathrm{b}} \\
\text { discarded eggs }\end{array}$ & Enteritidis & 2 \\
\hline Poultry & Heidelberg & 2 & Biological material & Panama & 2 \\
\hline Poultry & Bredeney & 1 & Biological material & Ohio & 1 \\
\hline Poultry & Corvallis & 1 & One day old chicken & Anatum & 1 \\
\hline \multicolumn{2}{|c|}{ Total NAL-resistant strains } & 107 & \multicolumn{2}{|c|}{ Total NAL-sensitive strains } & 16 \\
\hline
\end{tabular}

The strains were grown in BHI broth (Acumedia ${ }^{\mathrm{TM}}$ ) at $37^{\circ} \mathrm{C}$ for $18 \mathrm{~h}$ before extraction of the genomic DNA, according to Swanenburg et al. (17). The PCR reactions were performed in final volume of $25 \mu \mathrm{L}$, containing dNTPs (200 mM), $\mathrm{MgCl}_{2}$ (10 $\mathrm{mM})$, buffer for Taq $(10 \mathrm{mM})$, Taq-polymerase $(0.5 \mathrm{U})$ (Invitrogen ${ }^{\mathrm{TM}}$ ) and DNA (5 ng). The primers forward used were STGYRA1 and AS-81 at concentration 25 pMol each one. The STGYRA-HinfI/87 was the reverse primer for the reactions, used at concentration of $50 \mathrm{pMol}$ (7). For the RFLP reactions, $5 \mu \mathrm{L}$ of the PCR product was digested with $0.5 \mu \mathrm{L}$ of $\operatorname{HinfI}$ (Invitrogen ${ }^{\mathrm{TM}}$ ) in final volume of $7.5 \mu \mathrm{L}$, at $37^{\circ} \mathrm{C}$ for $2 \mathrm{~h}$. Ladder of molecular weight of $100 \mathrm{bp}$ and $25 \mathrm{bp}$ were used (Invitrogen ${ }^{\mathrm{TM}}$ ). After electrophoresis in agarose gel 3\%, the gels were treated with ethidium bromide, viewed under ultraviolet light (UV) and documented. The RFLP profile obtained for each strain was evaluated for the occurrence of mutations as per the size of fragments generated according to Giraud et al. (8).

In order to verify mutations associated with resistance to NAL in two resistant strains that had susceptible genotype in AS-PCR-RFLP, sequencing of part of the gyrA gene was performed. The fragments generated in PCR were purified with Concert TM TRapid PCR Purification System TM (GIBCO BRL, UK) and subsequently, the cloning was performed with the TOPO TA for sequencing kit (Invitrogen ${ }^{\mathrm{TM}}$ ), according to manufacturer's instructions. The sequencing was conducted with the DYEnamic TM ET dye Terminator Cycle Sequencing kit (Amersham, GE HealthCare) in MegaBace 1000 (Amersham - GE HealthCare). Quality of the sequences was evaluated in PhredPhrap-Consed. The sequences obtained were 
compared to those deposited in the database of the National Center for Biotechnology Information (NCBI). The bioinformatics analyses were performed with the ClustalW and Bioedit softwares, and with analysis in the databases of NCBI.

Salmonella spp. strains evaluated in this study showed, after PCR, a fragment of 195bp and another of 80bp. These results demonstrate no mutations in the Gly81 codon, since the PCR generates only a fragment of $195 \mathrm{bp}$ when this mutation is present (8). A genetic profile corresponding to the absence of mutations in QRDR of gyrA gene was obtained in RFLP for all suscetible strains tested. Among 107 NAL-resistant strains analyzed $98 \%(\mathrm{n}=105)$ showed mutations in the QRDR of gyrA gene (94 epidemic strains and 11 of poultry origin). Mutations in Asp87 and Ser83, respectively, occurred in 62\% and $38 \%$ of these strains. Interestingly, two of the NALresistant strains of poultry origin, serovars Bredeney (AL 285/03) and Corvallis (AL 297/06), showed restriction pattern corresponding to the absence of mutations. Figure 1 shows the fragments observed in the PCR for strains and RFLP profiles corresponding to the mutations detected, or absence of those in AS-PCR-RFLP.

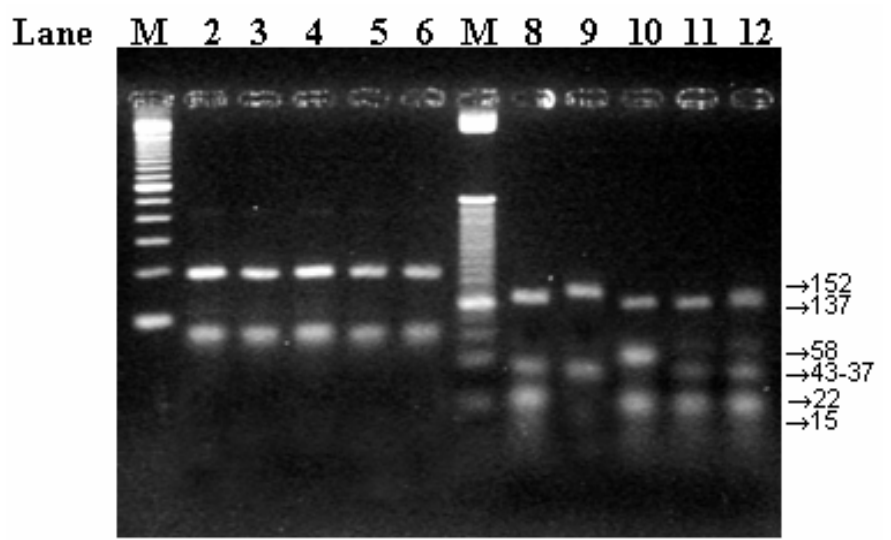

Figure 1. Considering reading from left to right: Lane 2 to 6: fragments resulting from PCR observed for all strains (195-80bp). Lane 8 to 12: fragments obtained after RFLP of the product of PCR with HinfI enzyme. Profile I (137-43-22-15 bp), lane 8, 11 and 12 correspond to the absence of mutations in the QRDR of gyrA. Profiles II (152-43-37 bp), lane 9, and III (137-58-22 bp) lane 10, represent mutations in codons Serine 83 and Aspartate 87, respectively. Lane 1 and 7 correspond to markers of molecular weight of $100 \mathrm{bp}$ and $25 \mathrm{bp}$, respectively.
The results observed in AS-PCR-RFLP are in agreement with reports that in NAL-resistant strains, the highest frequency of change occurs in codons Ser83 and Asp87 of the QRDR of gyrA gene (13). It is known that mutation in gyrA gene has been related to increased level of resistance to fluoroquinolones (7) and that concomitant alterations in these two residues are usually present in strains resistant to fluoroquinolones such as ciprofloxacin (18). In this study, two mutations were not found in any of the strains evaluated and all strains were susceptible to ciprofloxacin, according to the Clinical Laboratory Standards Institute $(4,15)$. However, 24 NAL-resistant strains, including the two strains that showed sensitivity profile in the RFLP, showed reduced susceptibility in the minimum inhibitory concentration of ciprofloxacin (CipMIC), with CipMICs between $0.125 \mathrm{~g} / \mathrm{mL}$ and $0.250 \mathrm{~g} /$ $\mathrm{mL}(15)$.

The main source of Salmonella infection for humans is chicken meat, pork, eggs and egg products $(5,16)$. The nontherapeutic use of fluroquinolones in veterinary medicine, as in prophylactic supplements or growth-promoting agents, can facilitate the selection of resistant bacteria or reduce susceptibility to these antimicrobials. Thus, the use of antimicrobial agents in animals raised for human consumption is, probably, the main cause for the increase and spread of resistant Salmonella strains $(7,9)$.

In the present study, two serovars of poultry origin, Corvallis (AL 297/06) and Bredeney (AL 285/03), showed CipMIC values of $0.250 \mathrm{~g} / \mathrm{mL}$ and $0.125 \mathrm{~g} / \mathrm{mL}$, respectively. In spite of these CipMIC values, the in silico analysis of $\mathrm{AL}$ 285/03 and AL297/06 strains revealed susceptible profile in the AS-PCR-RFLP. The reduced ciprofloxacin susceptibility, probably, could be related to other mechanisms like an overexpression of efflux pumps, porin down-regulation or plasmidmediated $(2,8)$. Another possibility are mutations out of the sequenced region like $g y r \mathrm{~B}$, parE or parC that have been identified with a lower frequency than gyrA mutations (7).

The sequenced fragment of NAL-resistant serovars $S$. Bredeney (GenBank accession $n^{\circ}$.GQ358014) and $S$. Corvallis (GenBank accession $\mathrm{n}^{\circ}$.GQ358015) strains, which showed 
genetic profile corresponding to the absence of mutation in RFLP and resistance of NAL, showed homology with a portion of the gyrA gene of $S$. Typhimurium deposited in NCBI. The alignment of sequences obtained with two sequences of $S$. Typhimurium (GenBank accession $\mathrm{n}^{\circ}$ AAB60062.1 and $\mathrm{n}^{\circ}$ CAA55580.1) revealed $100 \%$ of identity without nucleotide deletion, addition or substitution, excluding the nucleotide substitution of HinfI restriction site in the primer described by Giraud et al. (8). The sequenced region corresponds to partial portion of the gyrA gene located between amino acids 63 to 96, of which 30 amino acids correspond to the likely QRDR partial region. Indeed, it is reported that the QRDR region with higher frequency of mutations is between amino acids 67 and 106 in Salmonella spp. (7).

The AS-PCR-RFLP methodology used in this study was useful in detection of mutations that occur more frequently in Salmonella spp. The data presented here show a high incidence of point mutations in Salmonella strains belonging to different serovars and isolated from different origins and warn for the judicious use of quinolones in treatment of infections by Salmonella spp.

\section{ACKNOWLEDGMENTS}

The authors would like to thank Laboratorio Central do Parana (LACEN, Curitiba, Parana, Brazil) for the Salmonella epidemic strains and Dr. Alberto Bach for strains of poultry origin. Thanks to Laboratorio de Enterobacterias, Departamento de Bacteriologia da Fundação Oswaldo Cruz (FIOCRUZ, Rio de Janeiro, Brazil) for serotyping and phagotyping all Salmonella strains. Thanks to Conselho Nacional de Desenvolvimento Científico e Tecnológico, Brazil (CNPq) for graduate scholarship of R.B.S.; R.G.F. and M.M. This work was partially supported by CNPq (Process 476834/2004-0).

\section{REFERENCES}

1. Aznar, E.; Alarcón, T.; Buendía, B.; García-Peñuela, E.; Lopez-Brea, M. (2007). Detection of decreased susceptibility to fluoroquinolones in
Salmonella spp. by five different methods including real-time polymerase chain reaction (PCR). Int. J. Antimicrob. Agents. 30 (1), 67-71.

2. Cavaco, L.M.; Hasman, H.; Xia, S.; Aarestrup, F.M. (2009). qnrD, a novel gene conferring transferable quinolone resistance in Salmonella enterica serovar Kentucky and Bovismorbificans strains of human origin. Antimicrob Agents Chemother, 53 (2), 603-608.

3. Cebrian, L.; Sirvent, E.R.; Díaz, J.C. (2003). Characterization of Salmonella spp. mutants produced by exposure to various fluoroquinolones. Int. J. Antimicrob. Agents. 22 (2), 134-139.

4. Clinical and Laboratory Standards Institute. (2006). Performance Standards for Antimicrobial Susceptibility Testing. Sixteenth Informational Supplement, Document M100-S16, Wayne PA.

5. Conceição, R.C.S.; Moreira, A.N.; Ramos, R.J.; Goularte, F.L.; Carvalhal, J.B.; Aleixo, J.A.G. (2008). Detection of Salmonella sp in chicken cuts using immunomagnetic. Braz. J. Microbiol. 39: 173 - 177.

6. Eaves, D.J.; Randall, L.; Gray, D.T.; Buckley, A.; Woodward, M.J.; White, A.P.; Piddock, L.J.V. (2004). Prevalence of mutations within the Quinolone Resistance-Determining Region of gyrA, gyrB, parC e parE and association with antibiotic resistance in quinolone-resistant Salmonella enterica. Antimicrob. Agents Chemother. 48 (10), 4012-4015.

7. Giraud, E.; Baucheron, S.; Cloeckaert, A. (2006). Resistance to fluoroquinolones in Salmonella: Emerging mechanisms and resistance prevention strategies. Microbes and Infection. 8 (7), 1937-1944.

8. Giraud, E.; Brisabois, A.; Martel, J.L.; Chaslus-Dancla, E. (1999). Comparative studies of mutation in animal isolates and experimental invitro and in-vivo selected mutants of Salmonella spp. suggest a counter selection of highly fluoroquinolones-resistant strains in the field. Antimicrob. Agents Chemother. 43 (9), 2131-2137.

9. Hopkins, K.L.; Davies, R.H.; Threlfall, E.J. (2005). Mechanisms of quinolone resistance in Escherichia coli and Salmonella: Recent developments. Int. J. Antimicrob. Agents. 25 (5), 358-373.

10. Ling, J.M.; Chan, E.W.; Lam, A.W.; Cheng, A.F. (2003). Mutations in Topoisomerase Genes of Fluoroquinolone-Resistant Salmonellae in Hong Kong. Antimicrob. Agents Chemother. 47 (11), 3567-3573.

11. Piddock, L.V.J. (2002). Fluoroquinolone resistance in Salmonella serovars isolated from humans and food animals. FEMS Microbiol Rew. $26(1), 3-16$

12. Rotimi, V.O.; Jamal, W.; Pal, T.; Sonnevend, A.; Dimitrov, T.S.; Albert, M.J. (2008). Emergence of multidrug-resistant Salmonella spp. and isolates with reduced susceptibility to ciprofloxacin in Kuwait and the United Arab Emirates. Diagn. Microbiol. Infect. Dis. 60 (1), 71-77.

13. San-Martín, B.; Lapierre, L.; Toro, C.; Bravo, V.; Cornejo, J.; Hormazabal, J.C.; Borie, C. (2005). Isolation and molecular characterization of quinolone resistant Salmonella spp. from poultry farms. Vet. Microbiol. 110 (3-4), 239-244.

14. Soto, S.M.; Ruíz, J.; Mendoza, M.C.; Vila, J. (2003). In vitro fluoroquinolone-resistant mutants of Salmonella enterica serotype Enteritidis: Analysis of mechanisms involved in resistance. Int. J. Antimicrob. Agents. 22 (5), 537-540. 
15. Souza, R.B.; Ferrari, R.G.; Magnani, M.; Kottwitz, L.B.M.; Alcocer, I.; Tognim, M.C.B.; Oliveira, T.C.R.M. (2010). Ciprofloxacin susceptibility reduction of Salmonella strains isolated from outbreaks. Braz. J. Microbiol. 41, 497-500.

16. Sumner, J.; Raven, G.; Givney, R. (2004). Have changes to meat and poultry food safety regulation in Australia affected the prevalence of Salmonella or of salmonellosis? Int. J. Food Microbiol., 92(2), 199-205.

17. Swanenburg, M.; Urlins, H.A.P.; Keuzenkamp, D.A.; Snijders, J.M.A.
(1998). Validation of ERIC-PCR as a tool in epidemiology research of Salmonella in slaughter pigs. J. Ind. Microbiol. Biotechnol. 21 (3), 141144.

18. Turner, A.K.; Nair, S.; Wain, J. (2006). The acquisition of full fluoroquinolone resistance in Salmonella Typhi by accumulation of point mutations in the topoisomerase targets. J. Antimicrob. Chemother. 58 (4), 733-740. 